\title{
Further delays to full Agent Orange study
}

A study to investigate the health effects of Agent Orange on Vietnam War veterans is being obstructed by the US Department of Veterans Affairs (VA), claim scientists and veterans' organizations.

The department compensates veterans exposed to Agent Orange who have since gone on to develop conditions known to be linked to dioxins in the herbicide, such as nonHodgkin's lymphoma and soft-tissue cancer. But for many other diseases, the department says there is not enough evidence to establish a link. The list of diseases that are accepted for compensation purposes comes from betterdocumented studies on industrial and other accidental exposures to dioxins.

In 2003, the US Institute of Medicine (IOM) recommended that the VA should commission a large-scale, independent epidemiological study on how the herbicide affected the health of veterans. The recommendation received strong bipartisan backing by both congressional and Senate veterans committees. But five years later, the VA has yet to act, and instead has pursued its own $\$ 700,000$ internal study to 'validate' the models endorsed by the IOM. The VA also asked a different panel of experts at the IOM - not involved in Agent Orange research - to look again at whether such a study was needed. It reached much the same conclusions as the first panel.

"The whole thing makes me very sad, as we have lost five years," says Jeanne Stellman, an Agent Orange expert now at SUNY Downstate Medical Center in New York, who doubts
"There is an element of social justice, but ultimately, whether the study is pursued is a political question." data on the positions of individual troops and databases of the health of veterans and so make a study feasible, the IOM decided. In November 2003, a bipartisan group from the veterans committees of both the Congress and Senate requested the VA to "immediately contract with IOM to establish an \$8 million epidemiology research programme for independent investigators". But in a reply the following month, the then VA head Anthony Principi snubbed the request, declining to contract with the IOM, arguing that it was better placed to contract out that research itself. It has yet to do so.

The IOM's latest report says that the inhouse research the VA has launched cannot meet its stated goal of validating the model, is "insufficient" and "falls short of the complete array of work that the committee believes would be appropriate".

In testimony to the IOM panel last year, Mark Brown, director of the environmental agents section of the VA, said that he still considered an epidemiological study to be "a little naive... due to the lack of usable exposure and troop location data". Brown said that the department's existing approach to veteran compensation was adequate.

"Not to follow up on the Stellman work would be missing an opportunity," says David Savitz, chair of the IOM panel and an epidemiologist at Mount Sinai School of Medicine in New York. It would go some way to redressing the dearth of studies on herbicide exposure in veterans, Savitz that the department will ever support the study.

It was a paper by Stellman and her colleagues (J. M. Stellman at al. Nature 422, $681-687 ; 2003)$ that prompted the IOM's initial recommendations. Her team analysed data from flight records of US military aircraft and provided the most detailed computerized maps - or geographical information systems - of where, when and how much herbicide was sprayed in Vietnam. The US Air Force sprayed Agent Orange from 1961 to 1971 to wipe out the jungle vegetation concealing their Viet Cong opposition. Stellman's team calculated that four times more dioxin was sprayed than had previously been estimated.

Her system could allow researchers to combine says. It is not so much about dioxin science per se, for which much better data are available elsewhere, he says, but about learning more about the exposure and health of Vietnam veterans. There is an element of "social justice", he says, but ultimately, whether the study is pursued is also a political question.

Congress first mandated such a large-scale epidemiological study in 1979. But the US Centers for Disease Control and Prevention in Atlanta, Georgia, cancelled it, handing back much of the \$70-million funding, arguing that a pilot study showed that it was impossible to disentangle the effects of Agent Orange from other causes. Many politicians and scientists argued at the time that

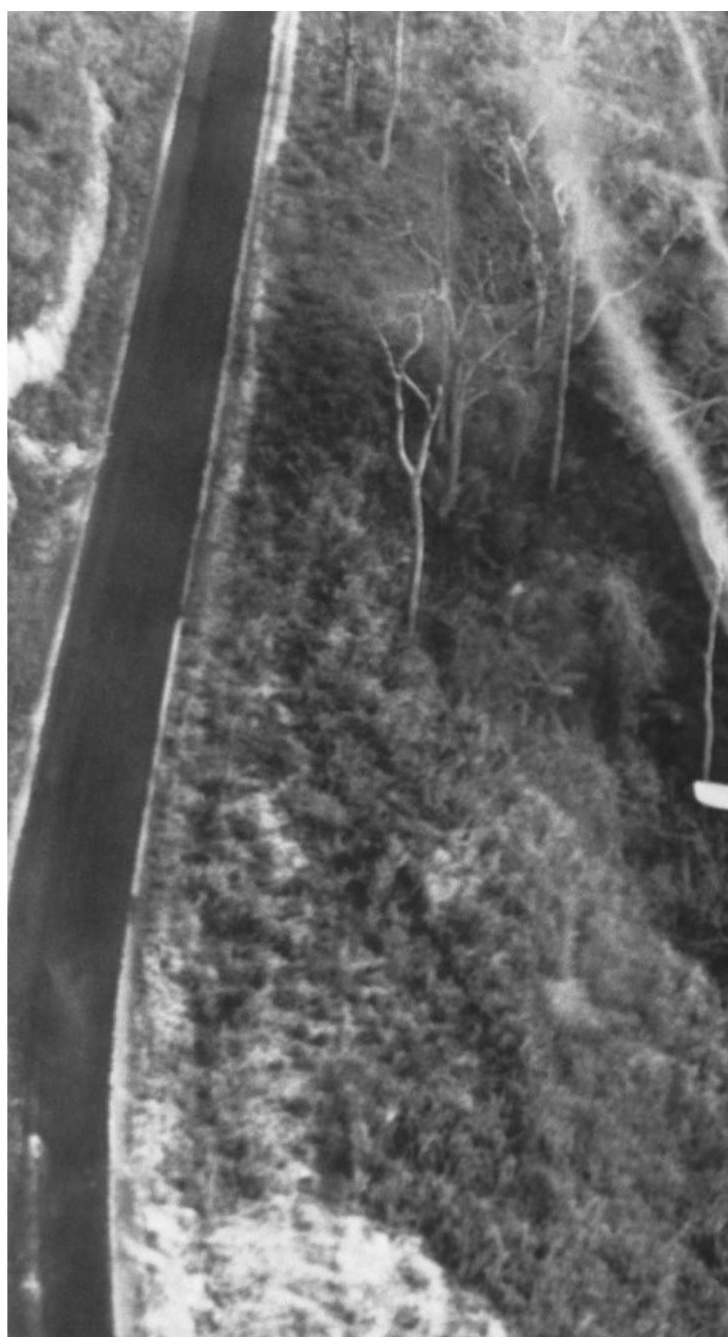

the study was politically rigged to fail.

In the latest twist, a paper published on 12 March in the Journal of Exposure Science and Environmental Epidemiology reports that the Stellman system overestimated the drift of her- 总 bicide from flight paths when compared with other crop-spraying aerial-dispersion models. The paper concludes that the system therefore "cannot be used to provide individual exposure estimates for the purpose of conducting epidemiologic studies". The work was sponsored by Monsanto and Dow Chemical Company, firms that manufactured Agent Orange and remain embroiled in lawsuits involving veterans.

The authors, from the consultancies M. E. Ginevan \& Associates in Silver Spring, Maryland, and Infoscientific.com in Carmichael, California, presented a draft of the paper to the IOM panel, which concluded that it did not seem to fundamentally detract from the model. Richard Clapp, an epidemiologist at Boston University in Massachusetts, says that he "is not impressed" by the new paper. "It strikes me as manufacturing uncertainty, and primarily 
